\title{
Review on the In Vitro Interaction of Insulin Glargine with the Insulin/Insulin-like Growth Factor System: Potential Implications for Metabolic and Mitogenic Activities
}

\author{
Authors \\ T. P. Ciaraldi ${ }^{1}$, T. Sasaoka ${ }^{2}$ \\ Affiliations \\ ${ }^{1}$ VA San Diego Healthcare System and University of California, San Diego, La Jolla, CA, USA \\ ${ }^{2}$ Department of Clinical Pharmacology, University of Toyama, Toyama, Japan
}

Key words
insulin
insulin analogues
insulin-like growth factor-1
mitogenicity

received 30.06 .2010

accepted 14.09.2010

Bibliography

DOI http://dx.doi.org/

10.1055/s-0030-1267203

Published online:

October 11, 2010

Horm Metab Res 2011;

43: $1-10$

(c) Georg Thieme Verlag KG Stuttgart · New York

ISSN 0018-5043

Correspondence

\section{T. P. Ciaraldi, PhD}

Department of Medicine

(9111G)

University of California

San Diego

9500 Gillman Drive

La Jolla

CA 92093

USA

Tel.: + 1/858/552 8585

ext. 6450

Fax: + 1/858/642 6242

tciaraldi@ucsd.edu

\section{Abstract}

$\nabla$

Insulin analogues provide clinically important benefits for people with diabetes, including more predictable action profiles and lower risk of hypoglycemia compared with human insulin. However, it has been suggested that certain insulin analogues may lead to greater activation of insulin-like growth factor-1 (IGF-1) signaling, with risk for adverse mitogenic effects. This article aims to critically review studies on the mitogenic effects of the insulin analogue insulin glargine (glargine) and its metabolites. A review of in vitro studies suggests that glargine may stimulate mitogenic activity in some cell lines at supraphysiological concentrations (nanomolar/micromolar concentrations). Mitogenicity appeared to be related to

\section{Introduction \\ $\nabla$}

Insulin analogues have recently come under scrutiny following the publication of 4 observational studies, which suggest a possible link between the use of insulin glargine and increased cancer risk [1-4]. These studies, however, are epidemiological, not randomized controlled trials and their findings must be interpreted with caution, as commented on by Smith and Gale [5]. Data from randomized clinical trials to date fail to support a relationship between insulin glargine use and increased cancer risk, although most of these trials are of short duration. The issue arose following preclinical evidence that some insulin analogues stimulate the proliferation and mitogenicity of some cell lines, stemming from evidence that $\mathrm{Asp}^{\mathrm{B} 10}$ insulin promoted tumor growth in vivo $[6,7]$. One hypothesis for this phenomenon is the cross-reactivity of insulin for the insulin-like growth factor-1 (IGF-1) receptor (IGF-1R), although this has yet to be definitively demonstrated. Therefore, the aim of this review is to characterize what effects insulin analogues, the expression of the IGF-1 receptor, being present in cells expressing high levels of the receptor and absent in cells with limited or no IGF-1 receptor expression. In animal studies, glargine did not promote tumor growth, despite administration at supraphysiological concentrations (nanomolar/ micromolar), which are unlikely to be observed in clinical practice because the doses needed to produce these concentrations are liable to lead to hypoglycemia. Furthermore, glargine in vivo is rapidly transformed into its metabolites, the metabolic and mitogenic characteristics of which have been shown to be broadly equal to those of human insulin. Thus, the suggestion of increased relative mitogenic potency of insulin glargine seen in some cell lines does not appear to carry over to the in vivo situation in animals and humans.

and in particular insulin glargine, have on cellular proliferation through actions at the IGF-1R.

\section{Insulin, Insulin-like Growth Factor-1 and Their Receptors \\ $\nabla$}

Human insulin (accession number: P01308) is a 51-amino acid protein composed of 2 chains, the A chain (21 amino acids) and the B chain (30 amino acids) and is derived from a 110-amino acid precursor. The insulin receptor (IR) (accession number: P06213) is a cell-surface receptor that contains 2 subunits ( $\alpha$ and $\beta$ ). The $\alpha$ subunit, comprising 731 amino acids is situated in the extracellular domain and contains the insulin binding sites. The $\beta$ subunit comprises 620 amino acids and has a membrane-spanning domain and intrinsic tyrosine kinase activity, which is involved in intracellular signal transduction.

The human IR is expressed as 2 isoforms, IR-A (short form) and IR-B (long form) $[8,9]$. There is considerable evidence that IR-A, which has the peculiar characteristic of being able to bind not 
only insulin but also insulin-like growth factor-2 (IGF-2), may play a critical role in the development of breast cancer [10] and other malignancies $[11,12]$. In addition, a role of the isoform IRA has been discussed for hybrid receptors, as increased expression of IR-A/IGF1R hybrids has been observed in tumors [13].

Human IGF-1 (accession number: P01343) consists of a single chain 70 amino acids long, and shares structural homology with insulin. The IGF-1 receptor (IGF-1R; accession number: P80869) comprises 2 subunits ( $\alpha$ and $\beta$ ), which share similar structural and functional homology with the IR. Indeed, the structural homology of IR and IGF-1R suggests that IGF-1 and insulin have affinity for both receptors, although the affinity of insulin for IR is approximately 100 - to 1000 -fold greater than for IGF-1R, and vice versa, meaning that at physiological concentrations, little receptor cross-talk occurs [14]. Another consequence of the structural homology of IR and IGF-1R is the formation of hybrid receptors, consisting of $\alpha$ and $\beta$ IR plus $\alpha$ and $\beta$ IGF-1R. These hybrid receptors behave like full IGF-1R with regard to binding affinities for IGF-1 and insulin, as well as downstream signaling [15].

Most mammalian cells express both the IR and the IGF-1R to varying degrees. Both receptors belong to the same tyrosine kinase family and share substantial structural homology $[8,16]$, but with distinct cellular functions responsible for predominantly metabolic regulation and mitogenic activity, respectively. Activation of IR and IGF-1R results in upregulation of a variety of intracellular processes, in part, through shared intracellular signaling pathways for metabolic and mitogenic processes ( $\bullet$ Fig. 1), the latter of which can result in the proliferation of cancers. The role of IGF-1 in the emergence of cancer is discussed in more detail elsewhere [17].

It has been suggested that targeted modifications to the B10 residue affects the affinity and potency of such an insulin analogue for the IR and IGF-1R $[18,19]$ whereas addition of residues at B31 or B32 may enhance the binding affinity of an insulin analogue only to the IGF-1R. By contrast, deletion of B26-B30 residues decreases binding affinity of insulin to the IGF-1R.

\section{Insulin Analogues and the Insulin/insulin-like Growth Factor-1 System \\ $\nabla$}

Insulin analogues offer significant advantages for the treatment of diabetes compared with human insulin, as they are associated with less variable pharmacokinetic and pharmacodynamic characteristics and have a more predictable duration of action [20]. As a result, insulin analogues are associated with lower risk of hypoglycemia and better glycemic control compared with human insulin [21]. However, the experience gained with the insulin analogue $\mathrm{Asp}^{\mathrm{B} 10}$ insulin (see below) suggests that some caution might be required when developing novel insulin analogues in terms of carcinogenicity.

One of the first recombinant insulin analogues developed was $A \mathrm{Ap}^{\mathrm{B} 10}$ insulin, which had a targeted substitution of the histidine residue at position 10 on the B-chain to aspartic acid. Insulin glargine differs from human insulin by a substitution at A21 (Asp to Gly) and addition of 2 Arg residues on the B chain (B31

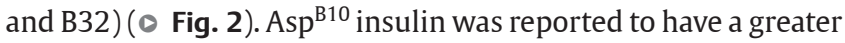
calculated potency relative to bovine insulin for binding to insulin receptors (IR) in rat liver plasma membrane fraction [22]. In vivo, this did not appear to translate to greater efficacy, as Asp ${ }^{\mathrm{B} 10}$ insulin was associated with rates of glucose utilization similar to human insulin [23] and, in pharmacodynamic studies, Asp ${ }^{\mathrm{B} 10}$ insulin was as effective as soluble human insulin [24,25]. However, it was subsequently found that $\mathrm{Asp}^{\mathrm{B} 10}$ insulin was associated with increased risk of carcinomas in the mammary glands of rats [6]. This phenomenon was supported by studies using a human breast epithelial cell line (MCF-10 cells) and a human breast cancer cell line (MCF-7 cells) showing that Asp ${ }^{\mathrm{B} 10}$ stimulated the growth of both cell types, although its mitogenicity was inhibited, but not abolished, when the cells were cultured with an antibody to the IGF-1R [7]. Asp ${ }^{\mathrm{B} 10}$ insulin was found to have a greater affinity for the IGF-1R compared with human insulin [7] as well as a 10-fold longer dissociation kinetic than human insulin for the IR [26]. Thus, the mitogenic activity of $\mathrm{Asp}^{\mathrm{B} 10}$ reflects its capacity to activate IR with an increased residence time as well as potentially activating IGF-1R [27]. In contrast, the frequently hypothesized mechanism for the increase in cell proliferation in response to treatment with insulin glargine is based only on increased affinity for IGF-1R, and not on increased IR activation or prolonged IR occupancy.

This review does not intend to provide detailed summaries of signaling pathways, as there are numerous reviews already available $[28,29]$. Instead, we examine the precise nature of the affinity and efficacy of insulin analogues, in particular insulin glargine, for the IGF-1R, and to evaluate the implications for mitogenesis and carcinogenicity with these analogues.

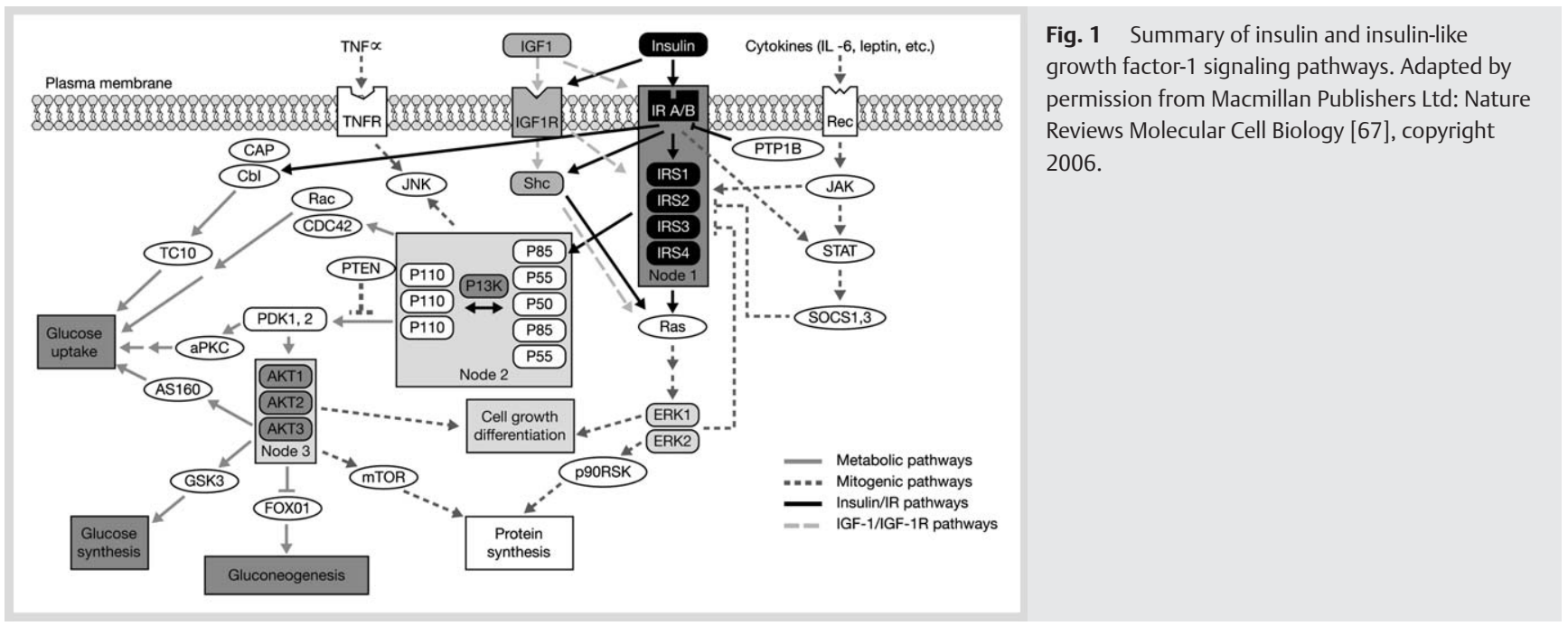




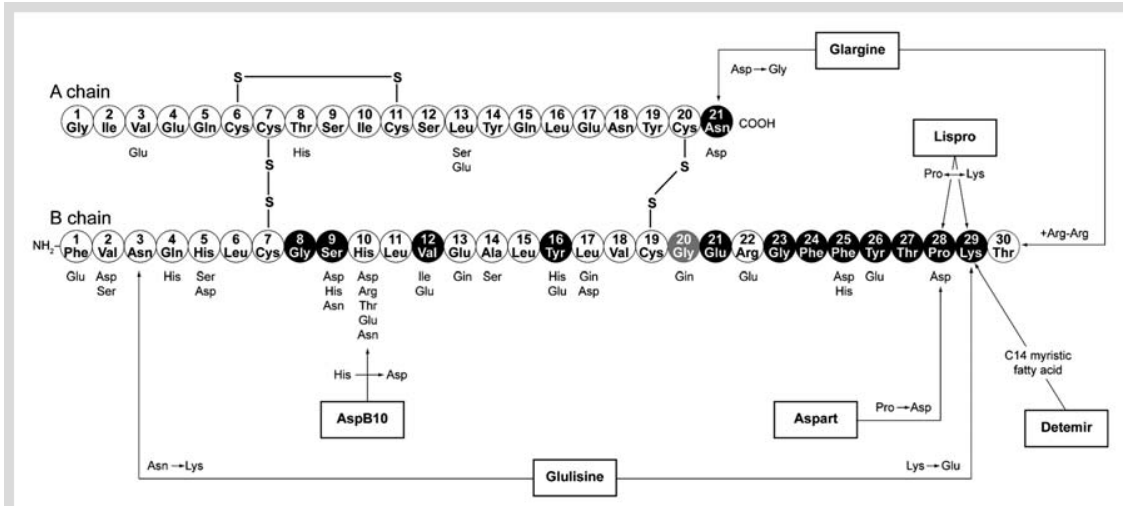

Fig. 2 Schematic diagram showing the modifications to the insulin structure to generate the longacting and rapid-acting insulin analogues.

Table 1 Degradation products of insulin glargine at the site of injection ${ }^{\text {a }}$

\begin{tabular}{|c|c|c|c|c|}
\hline Subject & Time & $\begin{array}{l}\text { Insulin }^{\dagger} \\
\text { ( } \mu \text { g equiv/ } \\
\text { sample }^{\ddagger} \text { ) }\end{array}$ & $\begin{array}{l}\text { Insulin } \\
\text { glargine } \\
(\%)\end{array}$ & $\begin{array}{l}\text { M1/M2 } \\
\text { (\%) }\end{array}$ \\
\hline A & $00: 00 \mathrm{~h}$ & 0 & - & - \\
\hline B & $02: 00 \mathrm{~h}$ & 1.1 & 10 & 90 \\
\hline C & $06: 00 \mathrm{~h}$ & 4.4 & 57 & 43 \\
\hline D & $12: 00 \mathrm{~h}$ & 3.3 & 51 & 49 \\
\hline E & $24: 00 \mathrm{~h}$ & 2.6 & 81 & 20 \\
\hline Mean percentage & & & 50 & 50 \\
\hline
\end{tabular}

a Determined by chromatographic separation

$\dagger$ Estimated from amounts for immunoreactive species in high-performance liquid chromatography eluates

$\ddagger$ Approximately $1-4 \mathrm{~g}$ of tissue. Reproduced from Kuerzel et al. [30] by permission of the publisher (Taylor \& Francis Group, http://www.informaworld.com)

\section{Literature Search Methods}

\section{$\nabla$}

Medline/PubMed was searched to identify publications relating to insulin, IR, IGF-1, IGF-1R, insulin glargine and mitogenicity using in vitro, ex vivo or in vivo activation of the IGF-1R. The results of these studies are discussed below.

\section{Results \\ $\nabla$}

\section{Metabolism of insulin glargine}

Before we discuss the in vitro and in vivo effects of insulin glargine, we first wish to describe the metabolism of insulin glargine. Of note, the modifications made to insulin glargine are essential for the formation of a stable precipitate upon injection. However, the dissociation rate is slow and the dissociated insulin molecules are actually released by proteolytic degradation of the parent molecule into 2 principal metabolites, namely M1 ([Gly $\left.{ }^{\mathrm{A} 21}\right]$ insulin) and M2 ([Gly ${ }^{\mathrm{A} 21}$, des-Thr $\left.{ }^{\mathrm{B} 30}\right]$ insulin), which are formed by the sequential removal of the 2 Arg residues from the carboxy terminus of the B-chain and deamination of the Thr residue in position $B 30$ [30]. It has been demonstrated that the parent product and the M1 and M2 metabolites are biologically active, and are structurally similar to human insulin. It also seems that the generation of these metabolites following subcutaneous injection of insulin glargine is likely to be initiated at the site of injection and continued within the circulatory system because, in healthy volunteers, an average ratio of 50:50 for insulin glargine and the metabolites M1/M2 was observed at the site of injection ( 0 Table 1 ).
In vitro metabolism studies showed that, in the presence of serum, insulin glargine is rapidly processed to its main metabolites; M1 (GlyA21) and M2 (GlyA21desB30), with an average of $72 \%$ (range $46-98 \%$ ) of insulin glargine converted to M1 within $30 \mathrm{~min}[31]$.

\section{In vitro studies of insulin glargine}

Receptor-binding characteristics and the potential for IGF-1-like activity of insulin glargine

A number of in vitro studies, using cell lines, primary cell cultures or solubilized receptors, have evaluated the receptor-binding characteristics of insulin and insulin analogues for the IR and IGF-1R.

In a study by Bahr et al. [32], a competition assay using myoblasts was performed, using insulin glargine, $\mathrm{Asp}^{\mathrm{B} 10}$ insulin or IGF-1 at supraphysiological concentrations ( $1 \mathrm{nM})$ to displace radiolabeled human insulin or IGF-1 from the IGF-1R. Insulinlike growth factor was associated with the greatest displacement (40\%), followed by Asp ${ }^{B 10}$ insulin (25\%), insulin glargine (15\%), and then human insulin (5\%).

Binding of insulin and insulin analogues to the solubilized IR and IGF-IR has also been determined by Kurtzhals et al. [33] In this study, the receptors were isolated from transfected baby hamster kidney cells, and were incubated with insulin or IGF-1. The affinities of $\mathrm{Asp}^{\mathrm{B} 10}, \mathrm{Gly}^{\mathrm{A} 21}$ (a metabolite of insulin glargine), $\operatorname{di} \operatorname{Arg}\left(\operatorname{Arg}^{B 31}, \operatorname{Arg}^{B 32}\right.$ insulin), and insulin glargine for the solubilized IR and IGF-IR were then determined, relative to human insulin. Insulin glargine and $\mathrm{Asp}^{\mathrm{B} 10}$ insulin had a 0.9- and 2.1fold greater affinity for the IR and 5.9- and 6.4-fold greater affinity for the IGF-1R, respectively. The metabolic potencies of these agents (insulin-stimulated lipogenesis) were also determined in this study. Human insulin was associated with a 12-fold increase in lipogenesis, relative to basal levels. Insulin glargine was associated with a lower metabolic potency relative to human insulin, whereas Asp ${ }^{\mathrm{B} 10}$ insulin was associated with an increased metabolic potency. Asp ${ }^{\mathrm{B} 10}$ insulin is thought to trigger IR-A with even higher potency than IR-B. Consequently, Asp ${ }^{B 10}$ insulin could potentially stimulate proliferation of IR-A-expressing tumor cells. A direct test of this questions was provided by Sciacca et al. [34], who studied the binding and action of multiple insulin analogues in mouse fibroblasts engineered to express either IR$\mathrm{A}, \mathrm{IR}-\mathrm{B}$, or IGF-1R exclusively. While Asp ${ }^{\mathrm{B} 10}$ insulin bound to both IR-A and IR-B with a higher affinity than human insulin, the long-acting analogues insulin glargine and insulin detemir displayed lower affinities than human insulin for IR-A; both bound to IGF-1R with affinities 100-fold lower than IGF-1. 
The findings reported by Kurtzhals et al. contrast with those reported by Chisalita and Arnqvist [14], who determined relative potencies of human insulin, insulin glargine and IGF-1 in human dermal microvascular endothelial cells (hMVECs) and human aortic endothelial cells. In this study, the relative potencies of insulin and insulin glargine were reported by the authors to be 1000 - and 100-fold less, respectively, for the IGF-1R than with IGF-1, suggesting that insulin glargine would not elicit significant activation of the IGF-1R, except at supraphysiological levels.

In a study by Berti et al. [26], the receptor binding characteristics and rates of dissociation from the IR for human insulin, insulin glargine and $\mathrm{Asp}^{\mathrm{B} 10}$ insulin were determined using Rat-1 fibroblasts. For both insulin glargine and human insulin, the dissociation of insulin from the receptor was largely complete within a 120 -min period. In contrast, Asp ${ }^{\mathrm{B} 10}$ insulin exhibited only partial dissociation, with IR activation extending beyond $120 \mathrm{~min}$. The conclusion from multiple studies is that insulin glargine does not differ appreciably from human insulin in terms of its affinity for the IR. Insulin glargine has a higher affinity for the IGF-1R (10 times higher overall than human insulin); however, this affinity remains 100 times weaker than that of native IGF-1.

Induction of mitogenicity, cell growth, and proliferation by insulin glargine and human insulin compared with IGF-1

In the studies described above, it was reported that insulin analogues tend to show greater affinity for the IGF-1R relative to human insulin, which may relate to the modifications made to the insulin analogues (as summarized in $\bullet$ Fig. 2). However, the affinity for a receptor does not necessarily equate to efficacy and, thus, potency. Therefore, markers of mitogenicity, including DNA replication and cellular growth, have been examined using in vitro models of cell growth to determine the mitogenic effects of insulin and insulin analogues. One in vitro marker that has been used extensively for this purpose is radiolabeled ${ }^{3} \mathrm{H}$-thymidine incorporation.

Slieker et al. [19] determined the mitogenicity of insulin and insulin analogues using human mammary epithelial cells (HMECs). In this study, the relative potency of diArg (9.2- and 21.8-fold, respectively) and $\mathrm{Asp}^{\mathrm{B} 10}$ insulin (3.4- and 3.8-fold, respectively) for IGF-1R binding and HMEC growth was greater than that of human insulin. Nevertheless, these potency values were still substantially lower than the relative potencies of IGF-1 for cell growth (57-fold) and IGF-1R binding (1324-fold). However, these findings cannot be translated to insulin glargine itself, because the presence of Gly at A21 was shown to reduce the affinity of Gly ${ }^{\mathrm{A} 21}$ insulin for the IGF-1R [33] and because insulin glargine had lower affinity for the IGF-1R than did diArg insulin $[19,33]$. Kurtzhals et al. investigated the mitogenic effect $\left({ }^{3} \mathrm{H}-\right.$ thymidine incorporation) of insulin using human osteosarcoma cells (Saos-2), which showed a greater abundance of IGF-1Rs than IRs [33]. IGF-1, as a positive control, stimulated growth at a substantially lower effective concentration $\left(\mathrm{EC}_{50}: 50 \mathrm{pmol} / \mathrm{l}\right)$ compared with human insulin $\left(\mathrm{EC}_{50}: 4 \mathrm{nmol} / \mathrm{l}\right)$. Thus, in this study, human insulin required a $\sim 100$-fold greater concentration than IGF-1 to elicit a similar increase in growth. Although insulin glargine and $\mathrm{Asp}^{\mathrm{B} 10}$ insulin were associated with greater mitogenic potency relative to human insulin, a 100 -fold greater concentration was required than for IGF-1.

Similarly, Bahr et al. [32], who investigated IGF-1R-mediated growth and differentiation of cardiac myoblasts and adult rat ventricular cardiomyocytes showed that $\mathrm{Asp}^{\mathrm{B} 10}$ insulin elicited a 3 -fold increase in ${ }^{3} \mathrm{H}$-thymidine incorporation (relative to human insulin), which was similar to that elicited by IGF-1. By contrast, insulin glargine was equipotent to human insulin for this mitogenic effect.

A study by Weinstein et al. [35] compared the effects of regular insulin and the analogues insulin glargine, detemir, lispro, and aspart with IGF-1 in stimulating proliferation of cancer-derived cell lines from the colon (HCT116), prostate (PC3), and breast (MCF-7). Cells were incubated at $100 \mathrm{nM}$ of the respective insulin, and mitogenic effect was assayed via cell count. Regular insulin and insulin aspart were reported to have little mitogenic effect, whereas insulin glargine, insulin detemir and insulin lispro stimulated proliferation in all 3 cell lines, albeit to a lesser extent than did IGF-1. Further investigation indicated that this mitogenic effect of the insulin analogues was dose dependent; lower doses (20-50 nM) led to minimal increases in cell numbers. Conversely, the mitogenic effect of IGF-1 was seen regardless of dose. Notably, in this study, the effects of insulin glargine were more pronounced in MCF-7 cells than in the other cell lines.

The observation of increased proliferation of MCF-7 cells was also found in recent studies by Mayer et al. [36] and Shukla et al. (๑ Fig. 3) [37], which showed mitogenic potency of insulin analogues (long and short acting) at physiologically relevant concentrations on mammary epithelial cells. Both studies showed that the differences in mitogenicity between the insulin analogues were low, with only insulin glargine reaching significance for inducing higher proliferation of MCF-7 breast cancer cells. By contrast, all insulins stimulated the proliferation of MCF-10 cells to a similar level. Moreover, Mayer et al. noted that the MCF-7growth stimulating properties of insulin glargine were less potent compared with IGF-1 and that the effects were less marked in MCF-10 cells. The different responses in MCF-10 and MCF-7 cells were proposed to be related to differences in relative IGF-1R and IR expression. This concept was tested further in the study by Shukla et al., who established IGF-1R-knockout MCF-7 cells. IGF-1R knockout substantially reduced the proliferative responses of these cells to insulin glargine, which elicited responses equipotent to those of human insulin [37]. Conversely, insulin glargine and insulin detemir were both able to stimulate the growth of mouse fibroblasts to greater extent than native insulin in the presence of either IR-A, IR-B or IGF-1R; IGF-1 stimulated proliferation only in cells containing IGF-1R [34].

However, the findings of Shukla et al. are inconsistent with those reported by Staiger et al. [38], who compared the mitogenic potency $\left({ }^{3} \mathrm{H}\right.$-thymidine incorporation) of insulin glargine, human insulin and a negative control in MCF-7 and MCF-10 cells. Although MCF-10 cells showed enhanced ${ }^{3} \mathrm{H}$-thymidine incorporation with insulin glargine, this was not significantly different from that elicited by human insulin. Similarly, although MCF-7 cells showed enhanced ${ }^{3} \mathrm{H}$-thymidine incorporation in response to insulin glargine and regular insulin, this was not significantly different between the 2 insulins. Meanwhile, Liefvendahl and Arnqvist [39] examined the effect of insulin glargine on cell growth in the breast cancer cell lines MCF-7 and SKBR-3 and the osteosarcoma cell line Saos-2. Insulin, IGF-1, and insulin glargine all showed mitogenic effect (measured via increased DNA synthesis) at concentrations higher than $10 \mathrm{nmol} / \mathrm{l}$, but no significant differences were found between insulin glargine and regular insulin. In addition, insulin and insulin glargine were also comparable in their ability to augment the proliferation of 


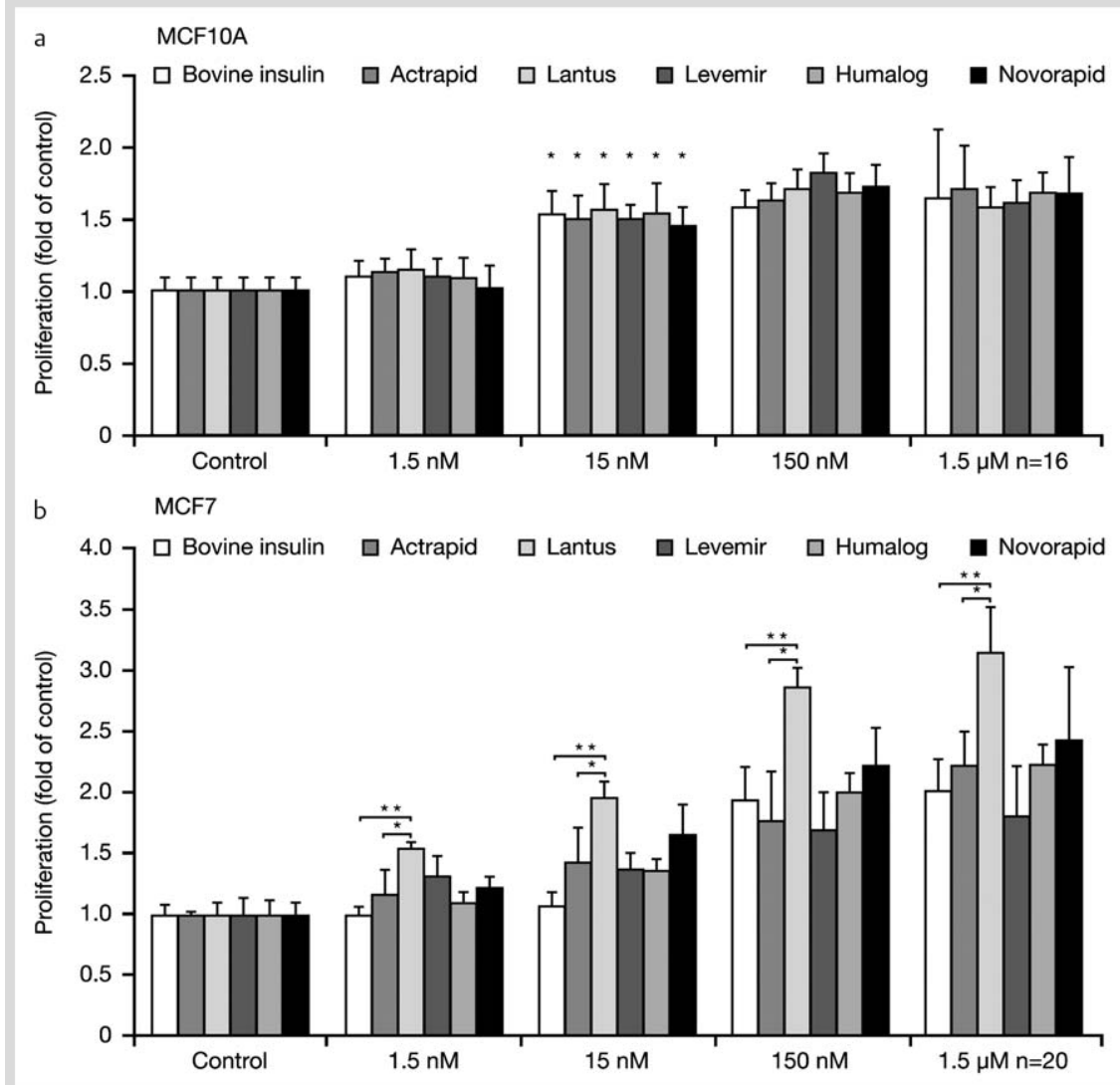

Fig. 3 Proliferative ability of insulin and insulin analogues in MCF-10A and MCF-7 cells. Adapted by permission from The Society for Endocrinology: Endocrine-Related Cancer [37], copyright 2009.

benign rat epithelial thyrocytes and a human follicular thyroid cancer cell line (FTC-133) [40].

Other studies have evaluated the effects of IGF-1 and insulin glargine in other cell lines. For example, Chisalita and Arnqvist [14] investigated the effects of IGF-1, human insulin and insulin glargine on cellular growth of hMVECs. ${ }^{3} \mathrm{H}$-Thymidine incorporation was significantly $(\mathrm{p}<0.01)$ stimulated almost 2 -fold by IGF-1 at a concentration of $10^{-7} \mathrm{M}$, but at lower concentrations $\left(10^{-8}\right.$ and $\left.10^{-9} \mathrm{M}\right)$, the effect was less pronounced $(\sim 1.4-$ and $\sim 1.6$-fold increase, respectively, vs. unstimulated cells). In contrast, neither insulin nor insulin glargine were associated with significant increases in either ${ }^{3} \mathrm{H}$-thymidine or ${ }^{3} \mathrm{H}$-glucose incorporation into hMVECs. Meanwhile, Staiger et al. [41], incubated human coronary artery endothelial cells and human coronary artery smooth muscle cells in basal medium or in medium supplemented with either regular insulin or insulin glargine in growth medium. The growth medium stimulated incorporation of ${ }^{3} \mathrm{H}$-thymidine by $>2.5$-fold compared with the basal medium in both cell types. In contrast, neither human insulin nor insulin glargine affected ${ }^{3} \mathrm{H}$-thymidine incorporation (i.e., no increase in cell growth). Similar results were reported by Chisalita et al. [42], although this study did not address the effect of insulin analogues. The study used human aortic smooth muscle cells (hASMCs) and demonstrated that both IGF-1 and IGF-2 activated the IGF-1R and stimulated glucose metabolism and DNA synthesis in hASMCs, while insulin had little effect in these cells. Separate from the lack of direct effects of insulin and insulin glargine on mitogenesis in hMVEC, multiple insulin analogues were shown to increase capillary-like tube formation by these cells when added together with bFGF+TNF- $\alpha$ [43]. Such a potential stimulation of angiogenesis could augment tumor progression even in the absence of effects on proliferation. Both short- and long acting insulin analogues, including insulin glargine, were similar to native insulin in inducing this response.

We evaluated the mitogenic potency, again in terms of ${ }^{3} \mathrm{H}$-thymidine incorporation, of insulin glargine vs. human insulin in human skeletal muscle cells obtained from people who were either nondiabetic or had type 2 diabetes [44]. Overall, the mitogenic activity elicited by insulin glargine and human insulin was similar in both diabetic and nondiabetic muscle cells, while the greatest mitogenic activity resulted from IGF-1.

Eckardt et al. [45] used primary and secondary cultures of fibroblasts and skeletal muscle cells, which were treated with: regular insulin; $\mathrm{Asp}^{\mathrm{B} 10}$ insulin; insulins glargine, glulisine, lispro, and aspart; or IGF-1. In this study, although insulin analogues tended to result in stimulation of DNA synthesis, this occurred at concentrations of 10 or $100 \mathrm{nmol} / \mathrm{l}$. Moreover, the response varied between donors, which may have been due to the differential IGF-1R expression found between cells from the donors.

Wada et al. [46] compared the intracellular signaling properties of insulin glargine and insulin detemir with regular insulin in 3T3-L1 adipocytes, L6 myocytes, rat primary hepatocytes and vascular smooth muscle cells from rat aortas. In this study, the phosphorylation of IR, insulin receptor substrate (IRS)-1, and the downstream signaling molecules Akt, GSK3 and MAPK, was induced in a dose-dependent fashion and was similar with either insulin glargine or regular insulin, while insulin detemir was associated with a reduced effect in all cell cultures examined. Furthermore, 5-bromo-2'-deoxyuridine (BrdU) incorporation was similar with all 3 insulins in vascular smooth muscle cells. Thus, this study provided additional evidence that in many cell types the analogues insulin glargine and insulin detemir have a similar action in vitro to that of regular insulin regarding mitogenic potential. 
Consistently, the studies described above have shown that concentrations of insulin glargine or human insulin must be at least 50 - to 100 -fold greater than is required for IGF-1, to elicit a 'meaningful' increase in mitogenic or metabolic activities of some cell lines. In fact, the most marked effects of insulin glargine on mitogenicity appeared to be related to the expression of IGF-1R, as in MCF-7 and Saos-2 cells, and to the fact that knockout of the IGF-1R in MCF-7 cells reduced the effects of insulin glargine [37]. Thus, it seems unlikely that insulin would enhance IGF-1R-mediated signaling pathways under physiological conditions. Interestingly, the instances where insulin glargine has been found to have a greater mitogenic potency relative to human insulin, though still far lower than that of IGF-1, occurred in cancer cell lines $[33,35,36]$, whereas others found no differences between insulin glargine and insulin [38-40,47].

\section{Insulin glargine metabolites and relationship to} mitogenesis, cell growth, and proliferation

In the studies reviewed above, the mitogenic effects of insulin glargine were assessed for the parent product (i.e., $\left[\mathrm{Gly}^{\mathrm{A} 21}, \mathrm{Arg}^{\mathrm{B} 31}, \mathrm{Arg}^{\mathrm{B} 32}\right]$ insulin) and for selected insulin analogues with related structural sequences, such as diArg insulin, $\operatorname{Arg}^{\mathrm{B} 31}$ insulin and $\mathrm{Arg}^{\mathrm{B} 32}$ insulin. However, these analogues are not metabolites or derivatives of insulin glargine, because of the amino acid substitution at position 21 on the A chain (Asp $\rightarrow$ Gly). In fact, in the study by Kurtzhals et al. previously mentioned, it was shown that one (M1: GlyA21) of the 2 main metabolites of insulin glargine had substantially reduced IGF-1R affinity and mitogenic potency relative to human insulin (42 and 34\%, respectively) [33]. Hence, although the parent form of insulin glargine may show greater affinity to IGF-1R because of the presence of 2 Arg molecules on the B chain, this affinity is reversed by the presence of Gly at position A21.

In addition, a recent study has investigated the effects of these metabolites in terms of receptor affinity and mitogenicity [48]. In this study, human insulin, insulin glargine and its metabolites were compared in terms of affinity for IR isoforms and IGF-1R, receptor autophosphorylation, metabolic response, and mitogenic activity. As described above, insulin glargine and the metabolites showed lower binding affinities to the IR, relative to human insulin, with no preference for either isoform, findings that were well correlated with their autophosphorylation and metabolic activities. Consistent with the studies above, insulin glargine showed higher affinity for IGF-1R than did human insulin, which resulted in a lower $\mathrm{EC}_{50}$ value for receptor autophosphorylation and more potent stimulation of thymidine incorporation in Saos-2 cells. Notably, however, the 2 main metabolites M1 and M2 had a significantly reduced affinity for IGF-1R and their metabolic and mitogenic potencies were broadly equal to human insulin [48].

In vivo studies of insulin analogues and carcinogenicity As discussed above, there is variability in the in vitro/ex vivo mitogenic effects of insulin analogues via the IGF-1R. Indeed, some studies reported that insulin analogues were associated with a greater mitogenic effect than was human insulin. However, in these studies the mitogenic effect was generally only observed at supraphysiological concentrations, and cancerderived cell lines were often used. Toxicological and carcinogenicity studies of insulin analogues have been performed to determine the in vivo effects, if any, of insulin analogues and, thus, establish whether or not there is an increased risk of cancer in animals, which might translate to risk in humans.

Repeated-dose toxicity studies have been conducted with insulin glargine vs. neutral protamine Hagedorn (NPH) insulin, saline or vehicle, to determine whether there is any evidence of increased toxicity with the use of insulin glargine in vivo, in a variety of animal models $[49,50]$. For example, in a study by Stammberger et al. [49], insulin glargine $(2,5$, or $12.5 \mathrm{U} / \mathrm{kg}$ in mice and rats), NPH insulin $(12.5 \mathrm{IU} / \mathrm{kg}$ in mice and $5 \mathrm{IU} / \mathrm{kg}$ in rats), saline or vehicle were administered once-daily to groups (50 per group) of male and female mice (NMRI mice) and rats (Sprague-Dawley and Wistar rats). In this study, while mortality rates over a period of 2 years were comparable between treatment groups in mice, they tended to be greater in saline-treated male and female mice compared with insulin-treated groups. In male rats, mortality was significantly increased in vehicle-, insulin glargine- and NPH insulin-treated rats compared with the saline control, and in female rats, mortality dose-dependently increased with insulin glargine [49].

Despite these observations, the incidence of specific tumors did not appear to be related to study medication. No consistent dosedependent increase in the incidence of tumors, including hepatocellular adenoma or carcinoma, malignant fibrous histiocytoma, mammary gland adenocarcinoma or malignant mammary gland adenoacanthoma was found in either male or female mice [49], with a similar pattern of results observed in rats [49].

\section{Clinical studies of insulin analogues and carcinogenicity}

As discussed above, some insulin analogues, in particular Asp ${ }^{B 10}$ insulin, may show a greater mitogenic risk profile compared with human insulin. However, as demonstrated in a toxicology and carcinogenicity study, the insulin analogues used in clinical practice, such as insulin glargine, show a comparably low risk of cancer to that of human insulin. Indeed, by far the most challenging problem was that of chronic hypoglycemia [51]. However, issues of particular note are that the concentrations of insulin and insulin analogues used in the studies described above were supraphysiological and that cell lines do not account for the complex interactions that occur in tumor cells and local tissue.

In everyday clinical use, the mean daily dose of insulin is unlikely to reach the concentrations used in the studies described above. In the Treat-to-Target trial, for example, the optimized mean daily doses of insulin glargine and NPH insulin at the end of the study were $0.48 \pm 0.01 \mathrm{U} / \mathrm{kg}(47.2 \pm 1.3 \mathrm{IU})$ and $0.42 \pm 0.01 \mathrm{IU} / \mathrm{kg}$ (41.8 $\pm 1.3 \mathrm{IU})$, respectively [52]. In a 24 -h pharmacokinetic/ pharmacodynamic study, administration of $0.5 \mathrm{U} / \mathrm{kg}$ insulin glargine resulted in peak plasma insulin concentrations of 150$200 \mathrm{pmol} / \mathrm{l}$. For comparison, after administration of $0.25 \mathrm{U} / \mathrm{kg}$ biphasic insulin aspart, the peak plasma insulin concentration reached $\sim 250 \mathrm{pmol} / \mathrm{l}$ at the first dose and $300 \mathrm{pmol} / \mathrm{l}$ at the second dose [53]. It seems unlikely that insulin or insulin analogues will reach a concentration sufficient to bind to and activate the IGF-1 receptor. For example, in the study by Kurtzhals et al. [33], human insulin bound to the IGF-1 receptor with an affinity of $200 \mathrm{nmol} / \mathrm{l}$, while that of insulin glargine was $\sim 31 \mathrm{nmol} / \mathrm{l}$, which is $\sim 150$-fold greater than the plateau concentration reached in the pharmacokinetic study [54]. Indeed, in a study by Li et al. [55], insulin was unable to bind to and activate the IGF-1R at physiological concentrations (100-500 pmol/l), but dosedependently activated the IGF-1R at supraphysiological concentrations $(1-5 \mathrm{nmol} / \mathrm{l})$. That the issue of dose requires close 
attention is supported by the findings of Mannucci et al. [56], where in a retrospective, case-control study of insulin-treated diabetic subjects, they found that cases with incident cancer had received higher mean daily doses of insulin glargine than controls. In humans, IGF-1 signaling is also implicated in the pathogenesis of diabetic retinopathy (DR), by promoting neovascularization [57-59]; thus, an alternative marker of mitogenicity is that of development or progression of DR in patients treated with insulin. In a recent analysis of 4 Phase III clinical trials of patients with Type 1 or Type 2 diabetes who were treated with either insulin glargine or NPH insulin, insulin glargine was not associated with increased risk of the development or progression of DR [60]. These data were recently supported in a 5-year prospective, randomized controlled trial in which over 1000 patients were randomized to receive either insulin glargine $(n=515)$ or NPH insulin $(n=509)$. In that study of patients without or with nonproliferative DR, the proportion of patients showing a 3 or more step progression in Early Treatment Diabetic Retinopathy Study scores was similar in both groups in the per-protocol (insulin glargine, $\mathrm{n}=53 / 374$ [14.2\%]; NPH insulin, $\mathrm{n}=57 / 363[15.7 \%])$ and intent-to-treat $(63 / 502[12.5 \%]$ vs. 71/487 [14.6\%]) populations [61].

A study has linked intensive insulin therapy with pancreatic carcinoma, through altered IGF-1 signaling [62]. However, in another study by Erbel et al. [47], use of insulin glargine, or regular human insulin at low physiological concentrations (0.01$1 \mathrm{nM})$ and at supraphysiological conditions (10-100 nM), was not associated with increased proliferation or apoptosis of Colo357 cells (human pancreatic carcinoma cells). The authors extended these in vitro findings into a clinical context by following over 22 months the clinical progress of patients undergoing total or partial pancreatectomy intended to resect pancreatic carcinoma. The median survival time was 15 months; survival was not altered in patients with diabetes receiving insulin glargine compared with patients receiving regular human insulin, or in patients who had pancreatic cancer but no diabetes [47].

In terms of the use of insulin glargine and possible associations with cancer, several registry studies have proposed an increased risk of cancer in patients treated with insulin glargine $[1,3,4]$. However, another such study performed at the same time showed no increased risk of cancer with insulin glargine compared with human insulin [2]. Hypothetically an association between insulin glargine and cancer is possible and could theoretically be mediated via the IGF-1 system. However, as described above, other factors should be considered when interpreting these registry studies. First, because the duration of follow-up was relatively short in these registry-based analyses, many cases of neoplasms may have been undetected before the index period. Second, intensive therapy with insulin glargine (i.e., insulin glargine in combination with other insulins) was associated with a trend towards a reduced risk for neoplasms relative to treatment with nonglargine-based therapy. Third, the studies included only limited adjustment for potential confounding factors, including lifestyle factors and other risk factors for malignancy. In fact, based on the studies described above, one could hypothesize that insulin glargine could promote breast cancer development by stimulating the proliferation of cancerous breast tissue. However, in the study by Currie et al., a prior solid tumor was the strongest predictor for progression to breast cancer during the index period, with a hazard ratio of 4.22 (95\% confidence interval $[\mathrm{Cl}]$ : 2.14-8.32). The corresponding hazard ratio was
0.86 (95\% CI: $0.42-1.75$ ) for insulin glargine therapy (vs. all other insulins) [2]. Such non-randomized trials have an inherent potential for both anticipated and non-anticipated bias. For example, in these community-based registries, it is possible that an association between insulin glargine and cancer could occur because patients with cancer may have tendency for hypoglycemia and so are preferentially treated with insulin glargine in order to avoid this complication.

Within the context of a randomized controlled trial, an analysis of the 5-year retinopathy study showed no differences between $\mathrm{NPH}$ insulin and insulin glargine in terms of diagnosis of any neoplasm $(n=57$ [11.1\%] vs. 62 [12.3\%]; relative risk: 0.90; 95\% CI: 0.64-1.26) [63]. A retrospective analysis of 31 studies sponsored by the manufacturer also revealed no difference between insulin glargine and the active comparator in terms of risk of neoplasms during the trial, with 45 and 46 patients reporting 52 and 48 cases of malignant cancer in the insulin glargine and comparator groups, respectively (relative risk: $0.90 ; 95 \% \mathrm{CI}$ : 0.60-1.36) [64]. However, it must be acknowledged that the majority of studies were of 6 months in duration and may not be sufficiently long for tumors to emerge while on treatment.

\section{Discussion \\ $\nabla$}

Insulin glargine and some other insulin analogues show a greater binding affinity to solubilized IGF-1Rs relative to human insulin [33], which may be a result of modifications at B31/B32 or B10. By contrast, modifications at A21 may reduce binding to IGF-1R. Other studies have confirmed this observation using cell-based assays $[14,33,34,38,41,44]$. However, these studies have also demonstrated that the relative affinity of insulin analogues for IGF-1R is still much lower than that of the natural ligand IGF-1. In a competitive binding study, a 100 -fold greater concentration of insulin or insulin glargine was required to elicit an effect similar to that of unlabeled IGF-1 to displace ${ }^{125}$ I-IGF-1 from the receptor [44].

Indeed, in the in vitro studies described, the concentration of insulin or insulin analogues required to elicit a response via the IGF-1R was much higher - typically supraphysiological - than that of IGF-1. It seems unlikely that the systemic concentration of insulin or insulin glargine would reach levels sufficient to induce significant mitogenic effects. Indeed, while exposure to supraphysiological doses of insulin is, in theory, possible, in clinical practice insulin overdose results in hypoglycemia. Furthermore, insulin glargine, in the presence of serum, is rapidly processed to its main metabolites, M1 and M2 [31]. Although insulin glargine, M1 and M2 have similar affinities for the insulin receptor as human insulin (and hence similar metabolic effects), insulin glargine has a higher affinity for IGF-1R than M1 or M2, suggesting that the metabolites have a reduced mitogenic potency [65]. Furthermore, the in vitro data from the study investigating the effects of insulin glargine and its metabolites in terms of mitogenicity and cell proliferation strongly suggest that the metabolites contribute with the same potency as insulin glargine to blood glucose control, while leading to significantly reduced growth-promoting activity [48]. Data in rodents and limited data in humans indicate that a similar biodegradation process occurs in vivo; however, at present, available data in humans do not allow precise conclusions on ratios between glargine and its metabolites to be drawn [30]. 
A recent review by Sandow [66], which discusses the growth effects of insulin and its analogues, concluded that they do not have carcinogenic activity. This theme is highlighted in the study by Stammberger et al. [49], which determined the mitogenic and carcinogenic potential for insulin glargine over a 2-year duration. In particular, the incidence of mammary gland adenocarcinomas or malignant mammary gland adenoacanthoma was no more common with insulin glargine vs. NPH insulin or saline solution.

The authors also reported that insulin glargine was comparable with NPH insulin and the vehicle, despite administration of insulin at doses of up to $12.5 \mathrm{U} / \mathrm{kg}$ in mice and rats, approximately 25-times the mean dose reached at the endpoint of the Treat-toTarget study $(0.48 \mathrm{U} / \mathrm{kg})$ [52]. In a meta-analysis of 4 clinical studies, the onset or progression of DR in patients with Type 1 or Type 2 diabetes was similarly low with insulin glargine and with NPH insulin [60]. This finding was supported by a 5 -year prospective randomized controlled trial, which showed comparably low rates of DR progression (and other assessments of retinopathy) with insulin glargine and NPH insulin [61]. Finally, the turnover of human pancreatic cancer cells was unaffected by insulin glargine, and survival of patients with pancreatic cancer after pancreatectomy surgery was not determined by the type of insulin used to treat Type 1 diabetes [47].

\section{Conclusions}

$\nabla$

Here, we have identified a number of in vitro and in vivo studies that have examined the mitogenic and metabolic effects of insulin glargine relative to human insulin and IGF-1. We found a highly consistent pattern across all the studies, that insulin glargine is not associated with increased mitogenic activity at physiological concentrations, for the majority of in vitro and in all in vivo studies. Mitogenic effects were only seen when insulin was administered at supraphysiological concentrations; one study did report that insulin glargine at physiological concentrations induced the proliferation of MCF-7 breast cancer cells compared with other long- and short-acting insulin analogues, albeit to a lesser extent than IGF-1. However, data are limited and the result in these cells requires further investigation to determine the differential effects that appear in some cell lines.

It has been shown that insulin glargine is rapidly transformed into its metabolites [31]. Recent in vitro data have now demonstrated a similar metabolic signaling and activity for insulin glargine and its metabolites. Importantly, at least one of these metabolites has been found to be less potent than intact insulin glargine and similar to native human insulin in mitogenic signaling and cell proliferation [33].

The in vitro results suggesting increased relative potency of insulin glargine in cancer cell lines do not appear for the most part, from the available data, to translate to the in vivo situation in animals and humans. This lack of correlation is possibly due in part to the fact that in vitro studies examine supraphysiological levels, which are not replicated in patients. Indeed, if such elevated concentrations were achieved clinically, perhaps the greatest concern would be the risk of hypoglycemia. Clinical evidence from a retrospective, pooled analysis of 31 randomized controlled trials ( 12 in Type 1 diabetes and 19 in Type 2 diabetes), which included a total of 10880 people, found no increase in the risk of cancer with insulin glargine vs. comparator treatments [64]. In addition, results of a 5-year prospective study showed no increased risk of mitogenicity in terms of DR or neoplasms for insulin glargine relative to NPH insulin in patients with Type 2 diabetes $[61,63]$. Therefore, although continuing studies will monitor mitogenicity over long-term use, current data suggest that binding of insulin glargine to the insulin or IGF-1 receptors seems to pose no greater risk for adverse mitogenic or metabolic effect vs. human insulin or NPH insulin, when used in people at physiological concentrations.

\section{Acknowledgements \\ $\nabla$}

The contents of this paper and opinions expressed within are those of the authors, and it was the decision of the authors to submit the manuscript for publication. All authors contributed to the writing of this manuscript, including critical review and editing of each draft, and approval of the submitted version. Editorial support was provided by Huw Jones Ph.D., Medicus International, and funded by sanofi-aventis.

\section{Disclosures \\ $\nabla$}

TP Ciaraldi has received honoraria for holding lectures for SanofiAventis in the past. T. Sasaoka has no conflict of interest relating to this manuscript.

\section{References}

1 Colhoun HM. Use of insulin glargine and cancer incidence in Scotland: a study from the Scottish Diabetes Research Network Epidemiology Group. Diabetologia 2009; 52: 1755-1765

2 Currie CJ, Poole CD, Gale EA. The influence of glucose-lowering therapies on cancer risk in type 2 diabetes. Diabetologia 2009; 52: 1766-1777

3 Hemkens LG, Grouven U, Bender R, Gunster C, Gutschmidt S, Selke GW, Sawicki PT. Risk of malignancies in patients with diabetes treated with human insulin or insulin analogues: a cohort study. Diabetologia 2009; 52: 1732-1744

4 Jonasson JM, Ljung R, Talback M, Haglund B, Gudbjornsdottir S, Steineck $G$. Insulin glargine use and short-term incidence of malignancies-a population-based follow-up study in Sweden. Diabetologia 2009; 52: $1745-1754$

5 Smith $U$, Gale EA. Does diabetes therapy influence the risk of cancer? Diabetologia 2009; 52: 1699-1708

6 Ebeling P, Tuominen JA, Koivisto VA. Insulin analogues and carcinoma of the breast. Diabetologia 1996; 39: 124-125

7 Milazzo G, Sciacca L, Papa V, Goldfine ID, Vigneri R. ASPB10 insulin induction of increased mitogenic responses and phenotypic changes in human breast epithelial cells: evidence for enhanced interactions with the insulin-like growth factor-I receptor. Mol Carcinog 1997; 18: 19-25

8 De Meyts P, Whittaker J. Structural biology of insulin and IGF1 receptors: implications for drug design. Nat Rev Drug Discov 2002; 1: 769-783

9 Kristensen C, Wiberg FC, Andersen AS. Specificity of insulin and insulinlike growth factor I receptors investigated using chimeric mini-receptors. Role of C-terminal of receptor alpha subunit. J Biol Chem 1999; 274: $37351-37356$

10 Sciacca L, Costantino A, Pandini G, Mineo R, Frasca F, Scalia P, Sbraccia $P$, Goldfine ID, Vigneri $R$, Belfiore A. Insulin receptor activation by IGFII in breast cancers: evidence for a new autocrine/paracrine mechanism. Oncogene 1999; 18: 2471-2479

11 Vella V, Pandini G, Sciacca L, Mineo R, Vigneri R, Pezzino V, Belfiore A. A novel autocrine loop involving IGF-II and the insulin receptor isoform-A stimulates growth of thyroid cancer. J Clin Endocrinol Metab 2002; 87: 245-254

12 Sciacca L, Mineo R, Pandini G, Murabito A, Vigneri R, Belfiore A. In IGFI receptor-deficient leiomyosarcoma cells autocrine IGF-II induces cell invasion and protection from apoptosis via the insulin receptor isoform A. Oncogene 2002; 21: 8240-8250

13 Frasca F, Pandini G, Scalia P, Sciacca L, Mineo R, Costantino A, Goldfine $I D$, Belfiore A, Vigneri R. Insulin receptor isoform A, a newly recognized, high-affinity insulin-like growth factor II receptor in fetal and cancer cells. Mol Cell Biol 1999; 19: 3278-3288 
14 Chisalita SI, Arnqvist HJ. Insulin-like growth factor I receptors are more abundant than insulin receptors in human micro- and macrovascular endothelial cells. Am J Physiol Endocrinol Metab 2004; 286: E896-E901

15 Belfiore A. The role of insulin receptor isoforms and hybrid insulin/IGFI receptors in human cancer. Curr Pharm Des 2007; 13: 671-686

16 Ullrich A, Gray A, Tam AW, Yang-Feng T, Tsubokawa M, Collins C, Henzel $W$, Le Bon T, Kathuria S, Chen E, Jacobs S, Francke U, Ramachandran J, Fujita-Yamaguchi Y. Insulin-like growth factor I receptor primary structure: comparison with insulin receptor suggests structural determinants that define functional specificity. Embo J 1986; 5: 2503-2512

17 LeRoith D, Yakar S. Mechanisms of disease: metabolic effects of growth hormone and insulin-like growth factor 1. Nat Clin Pract Endocrinol Metab 2007; 3: 302-310

18 Chisalita SI, Nitert MD, Arnqvist HJ. Characterisation of receptors for IGF-I and insulin; evidence for hybrid insulin/IGF-I receptor in human coronary artery endothelial cells. Growth Horm IGF Res 2006; 16 : 258-266

19 Slieker LJ, Brooke GS, DiMarchi RD, Flora DB, Green LK, Hoffmann JA, Long HB, Fan L, Shields JE, Sundell KL, Surface PL, Chance RE. Modifications in the B10 and B26-30 regions of the B chain of human insulin alter affinity for the human IGF-I receptor more than for the insulin receptor. Diabetologia 1997; 40: S54-S61

20 Guerci B, Sauvanet JP. Subcutaneous insulin: pharmacokinetic variability and glycemic variability. Diabetes Metab 2005; 31: 4S7-4S24

21 Bell DS. Insulin therapy in diabetes mellitus: how can the currently available injectable insulins be most prudently and efficaciously utilised? Drugs 2007; 67: 1813-1827

22 Schwartz GP, Burke GT, Katsoyannis PG. A superactive insulin: B10-aspartic acid]insulin(human). Proc Natl Acad Sci USA 1987; 84: 6408-6411

23 Ribel U, Hougaard P, Drejer K, Sorensen AR. Equivalent in vivo biological activity of insulin analogues and human insulin despite different in vitro potencies. Diabetes 1990; 39: 1033-1039

24 Kang S, Brange J, Burch A, Volund A, Owens DR. Absorption kinetics and action profiles of subcutaneously administered insulin analogues (AspB9GluB27, AspB10, AspB28) in healthy subjects. Diabetes Care 1991; 14: 1057-1065

25 Kang S, Creagh FM, Peters JR, Brange J, Volund A, Owens DR. Comparison of subcutaneous soluble human insulin and insulin analogues (AspB9, GluB27; AspB10; AspB28) on meal-related plasma glucose excursions in type I diabetic subjects. Diabetes Care 1991; 14: 571-577

26 Berti L, Kellerer M, Bossenmaier B, Seffer E, Seipke G, Haring HU. The long acting human insulin analog HOE 901: characteristics of insulin signalling in comparison to Asp(B10) and regular insulin. Horm Metab Res 1998; 30: 123-129

27 Bonnesen C, Nelander GM, Hansen BF, Jensen P, Krabbe JS, Jensen MB, Hegelund AC, Svendsen JE, Oleksiewicz MB. Synchronization in G0/G1 enhances the mitogenic response of cells overexpressing the human insulin receptor A isoform to insulin. Cell biology and toxicology 2010; 26: 293-307

28 LeRoith $D$, Roberts $C T$ Jr. The insulin-like growth factor system and cancer. Cancer letters 2003; 195: 127-137

29 Pollak M. Insulin and insulin-like growth factor signalling in neoplasia. Nature reviews 2008; 8: 915-928

30 Kuerzel GU, Shukla U, Scholtz HE, Pretorius SG, Wessels DH, Venter C, Potgieter MA, Lang AM, Koose T, Bernhardt E. Biotransformation of insulin glargine after subcutaneous injection in healthy subjects. Curr Med Res Opin 2003; 19: 34-40

31 Agin A, Jeandidier N, Gasser F, Grucker D, Sapin R. Glargine blood biotransformation: in vitro appraisal with human insulin immunoassay. Diabetes Metab 2007; 33: 205-212

32 Bahr M, Kolter T, Seipke G, Eckel J. Growth promoting and metabolic activity of the human insulin analogue [GlyA21, ArgB31, ArgB32] insulin (HOE 901) in muscle cells. Eur J Pharmacol 1997; 320: 259-265

33 Kurtzhals $P$, Schaffer L, Sorensen A, Kristensen C, Jonassen I, Schmid C, Trub T. Correlations of receptor binding and metabolic and mitogenic potencies of insulin analogs designed for clinical use. Diabetes 2000; 49: 999-1005

34 Sciacca L, Cassarino MF, Genua M, Pandini G, Le Moli R, Squatrito S, Vigneri $R$. Insulin analogues differently activate insulin receptor isoforms and post-receptor signalling. Diabetologia 2010; 53: 1743-1753

35 Weinstein D, Simon M, Yehezkel E, Laron Z, Werner H. Insulin analogues display IGF-I-like mitogenic and anti-apoptotic activities in cultured cancer cells. Diabetes Metab Res Rev 2009; 25: 41-49

36 Mayer D, Shukla A, Enzmann $H$. Proliferative effects of insulin analogues on mammary epithelial cells. Arch Physiol Biochem 2008; 114: $38-44$
37 Shukla A, Grisouard J, Ehemann V, Hermani A, Enzmann H, Mayer D. Analysis of signaling pathways related to cell proliferation stimulated by insulin analogs in human mammary epithelial cell lines. Endocr Relat Cancer 2009; 16: 429-441

38 Staiger K, Hennige AM, Staiger H, Haring HU, Kellerer M. Comparison of the mitogenic potency of regular human insulin and its analogue glargine in normal and transformed human breast epithelial cells. Horm Metab Res 2007; 39: 65-67

39 Liefvendahl E, Arnqvist HJ. Mitogenic effect of the insulin analogue glargine in malignant cells in comparison with insulin and IGF-I. Horm Metab Res 2008; 40: 369-374

40 Muller K, Weidinger C, Fuhrer D. Insulin glargine and insulin have identical effects on proliferation and phosphatidylinositol 3-kinase/AKT signalling in rat thyrocytes and human follicular thyroid cancer cells. Diabetologia 2010; 53: 1001-1003

41 Staiger K, Staiger H, Schweitzer MA, Metzinger E, Balletshofer B, Haring $H U$, Kellerer $M$. Insulin and its analogue glargine do not affect viability and proliferation of human coronary artery endothelial and smooth muscle cells. Diabetologia 2005; 48: 1898-1905

42 Chisalita SI, Johansson GS, Liefvendahl E, Back K, Arnqvist HJ. Human aortic smooth muscle cells are insulin resistant at the receptor level but sensitive to IGF1 and IGF2. J Mol Endocrinol 2009; 43: 231-239

43 Rensing K, Houttuijn Bloemendaal F, Weijers E, Richel D, Büller H, Koolwijk $P$, van der Loos C, Twickler T, von der Thüsen J. Could recombinant insulin compounds contribute to adenocarcinoma progression by stimulating local angiogenesis? Diabetologia 2010; 53: 966-970

44 Ciaraldi TP, Carter L, Seipke G, Mudaliar S, Henry RR. Effects of the long-acting insulin analog insulin glargine on cultured human skeletal muscle cells: comparisons to insulin and IGF-I. J Clin Endocrinol Metab 2001; 86: 5838-5847

45 Eckardt K, May C, Koenen M, Eckel J. IGF-1 receptor signalling determines the mitogenic potency of insulin analogues in human smooth muscle cells and fibroblasts. Diabetologia 2007; 50: 2534-2543

46 Wada T, Azegami M, Sugiyama M, Tsuneki H, Sasaoka T. Characteristics of signalling properties mediated by long-acting insulin analogue glargine and detemir in target cells of insulin. Diabetes Res Clin Pract 2008; 81: 269-277

47 Erbel S, Reers C, Eckstein V, Kleeff J, Buchler W, Nawroth PP, Ritzel RA. Proliferation of colo-357 pancreatic carcinoma cells and survival of patients with pancreatic carcinoma are not altered by insulin glargine. Diabetes Care 2008; 31: 1105-1111

48 Sommerfeld MR, Muller G, Tschank G, Seipke G, Habermann P, Kurrle R, Tennagels $N$. In vitro metabolic and mitogenic signaling of insulin glargine and its metabolites. PloS one 2010; 5: e9540

49 Stammberger I, Bube A, Durchfeld-Meyer B, Donaubauer H, Troschau G. Evaluation of the carcinogenic potential of insulin glargine (LANTUS) in rats and mice. Int J Toxicol 2002; 21: 171-179

50 Hofmann T, Horstmann G, Stammberger I. Evaluation of the reproductive toxicity and embryotoxicity of insulin glargine (LANTUS) in rats and rabbits. Int J Toxicol 2002; 21: 181-189

51 Stammberger I, Seipke G, Bartels T. Insulin glulisine - a comprehensive preclinical evaluation. Int J Toxicol 2006; 25: 25-33

52 Riddle M, Rosenstock J, Gerich J. Insulin Glargine 4002 Study Investigators: The Treat-to-Target Trial: randomized addition of glargine or human NPH insulin to oral therapy of type 2 diabetic patients. Diabetes Care 2003; 26: 3080-3086

53 Luzio S, Dunseath G, Peter R, Pauvaday V, Owens DR. Comparison of the pharmacokinetics and pharmacodynamics of biphasic insulin aspart and insulin glargine in people with type 2 diabetes. Diabetologia 2006; 49: 1163-1168

54 Lepore M, Pampanelli S, Fanelli C, Porcellati F, Bartocci L, Di Vincenzo A, Cordoni C, Costa E, Brunetti P, Bolli GB. Pharmacokinetics and pharmacodynamics of subcutaneous injection of long-acting human insulin analog glargine, NPH insulin, and ultralente human insulin and continuous subcutaneous infusion of insulin lispro. Diabetes 2000; 49: $2142-2148$

55 Li G, Barrett EJ, Wang H, Chai W, Liu Z. Insulin at physiological concentrations selectively activates insulin but not insulin-like growth factor I (IGF-I) or insulin/IGF-I hybrid receptors in endothelial cells. Endocrinology 2005; 146: 4690-4696

56 Mannucci E, Monami M, Balzi D, Cresci B, Pala L, Melani C, Lamanna C, Bracali I, Bigiarini M, Barchielli A, Marchionni N, Rotella CM. Doses of insulin and its analogues and cancer occurrence in insulin-treated type 2 diabetic patients. Diabetes Care 2010; 33: 1997-2003

57 Ruberte J, Ayuso E, Navarro M, Carretero A, Nacher V, Haurigot V, George $M$, Llombart C, Casellas A, Costa C, Bosch A, Bosch F. Increased ocular levels of IGF-1 in transgenic mice lead to diabetes-like eye disease. J Clin Invest 2004; 113: 1149-1157 
58 Rosenthal R, Wohlleben H, Malek G, Schlichting L, Thieme H, Bowes Rickman $C$, Strauss $O$. Insulin-like growth factor- 1 contributes to neovascularization in age-related macular degeneration. Biochem Biophys Res Commun 2004; 323: 1203-1208

59 Poulaki V, Joussen AM, Mitsiades N, Mitsiades CS, Iliaki EF, Adamis AP. Insulin-like growth factor-I plays a pathogenetic role in diabetic retinopathy. Am J Pathol 2004; 165: 457-469

60 Davis MD, Beck RW, Home PD, Sandow J, Ferris FL. Early retinopathy progression in four randomized trials comparing insulin glargine and Nph insulin. Exp Clin Endocrinol Diabetes 2007; 115: 240-243

61 Rosenstock J, Fonseca V, McGill JB, Riddle M, Halle JP, Hramiak I, Johnston $P$, Davis $M$. Similar progression of diabetic retinopathy with insulin glargine and neutral protamine Hagedorn (NPH) insulin in patients with type 2 diabetes: a long-term, randomised, open-label study. Diabetologia 2009; 52: 1778-1788

62 de Herder WW. Biochemistry of neuroendocrine tumours. Best Pract Res Clin Endocrinol Metab 2007; 21: 33-41
63 Rosenstock J, Fonseca V, McGill JB, Riddle M, Halle JP, Hramiak I, Johnston $P$, Davis $M$. Similar risk of malignancy with insulin glargine and neutral protamine Hagedorn (NPH) insulin in patients with type 2 diabetes: findings from a 5 year randomised, open-label study. Diabetologia 2009; 52: 1971-1973

64 Home PD, Lagarenne P. Combined randomised controlled trial experience of malignancies in studies using insulin glargine. Diabetologia 2009; 52: 2499-2506

65 Fawcett J, Tsui BT, Kruer MC, Duckworth WC. Reduced action of insulin glargine on protein and lipid metabolism: possible relationship to cellular hormone metabolism. Metabolism 2004; 53: 1037-1044

66 Sandow J. Growth effects of insulin and insulin analogues. Arch Physiol Biochem 2009; 115: 72-85

67 Taniguchi CM, Emanuelli B, Kahn CR. Critical nodes in signalling pathways: insights into insulin action. Nat Rev Mol Cell Biol 2006; 7: 85-96 